\title{
The dilemma of social media algorithms and analytics
}

\author{
Maria Petrescu ${ }^{1}$ Anjala S. Krishen ${ }^{2}$
}

Accepted: 27 October 2020 / Published online: 5 November 2020

(c) Springer Nature Limited 2020

The launch of the Netflix 2020 documentary on social media platforms, addiction, and privacy, called The Social Dilemma, has created a firestorm of discussions. Comments on the documentary span addiction and privacy, and ethical platform design; the documentary has also highlighted the polarization of opinions on social media. Filmmaker Jeff Orlowski explores modern social media platforms as business models based on algorithms that encourage addiction and privacy breaches as features of social media platforms (Girish 2020; Morgese 2020).

The reactions to the documentary range from consumers deciding to close their social media accounts to oppositional voices calling for freedom of speech and not censoring the media. To summarize some of the comments, we performed a semantic analysis of 8812 Twitter messages discussing the documentary from the beginning of October 2020. The resultant conceptual mapping analysis reveals the themes presented in Fig. 1. The results show that main tech companies, including Google, Facebook, and Twitter, and their level of data and information manipulation are a major focus of consumer comments. The manipulation of algorithms and the resultant impact on society are also among the themes discussed. Interestingly, the topic of books surfaces in relation to censorship, freedom of speech, and knowledge.

In the context of data algorithms and analytics research, this documentary opens up discussion and controversy around how academia, research organizations, practitioners, and policymakers should partake in collaborative solutions (Krishen et al. 2017; Morgese 2020). Previous research on legalized data control shows inconclusive results in the

Maria Petrescu

mpetrescu@monaco.edu

Anjala S. Krishen

anjala.krishen@unlv.edu

1 Inseec U. Research Center, International University of Monaco, Monaco, Monaco

2 Lee Business School, University of Nevada Las Vegas, Las Vegas, USA world of digital ads, for example, with greater legal control lowering advertising effectiveness (Martin and Murphy 2017), and perceived privacy increasing click rate on personalized ads (Tucker 2014). However, the regulation of digital information privacy is dependent on national differences and systems and difficult to implement and enforce across jurisdictional boundaries (Petrescu and Krishen 2018; Petrescu et al. 2020).

Moreover, perhaps not coincidentally, the presence of the underlying theme of books in Twitter consumer discussions emphasizes the difficulty of censoring and manipulating knowledge even from ancient times, when "nonconforming" books were burned in public markets. While some voices call for stricter regulations of social media content, others call for the end of censorship in social media. Those who voice opposition to strict regulations suggest a restructured type of social platform and improved social algorithms that no longer use AI to make decisions about when and what to censor (Morgese 2020). The Persuasion Knowledge Model argues that consumers must be given the necessary opportunities and tools to learn about manipulation and persuasion from social interactions, which would shape how they respond as persuasion targets (Friestad and Wright 1994, 1995; Kirmani and Campbell 2004).

Therefore, we make a call for more research on the models and frameworks that can enhance and improve the business models and algorithms of social media platforms. As social media offerings continue to develop, effective collaboration among all stakeholders can enable a broader, ecosystems view of social media platforms; these discussions can identify a middle ground on privacy, ethical platform design, monetized services, and consumer awareness (Raschke et al. 2014). Additional research on the use of analytics by various stakeholders (e.g., businesses, education organizations, and policymakers), algorithm bias, and legal reform, can contribute to the development of ethical solutions to social media content and platform designs. 


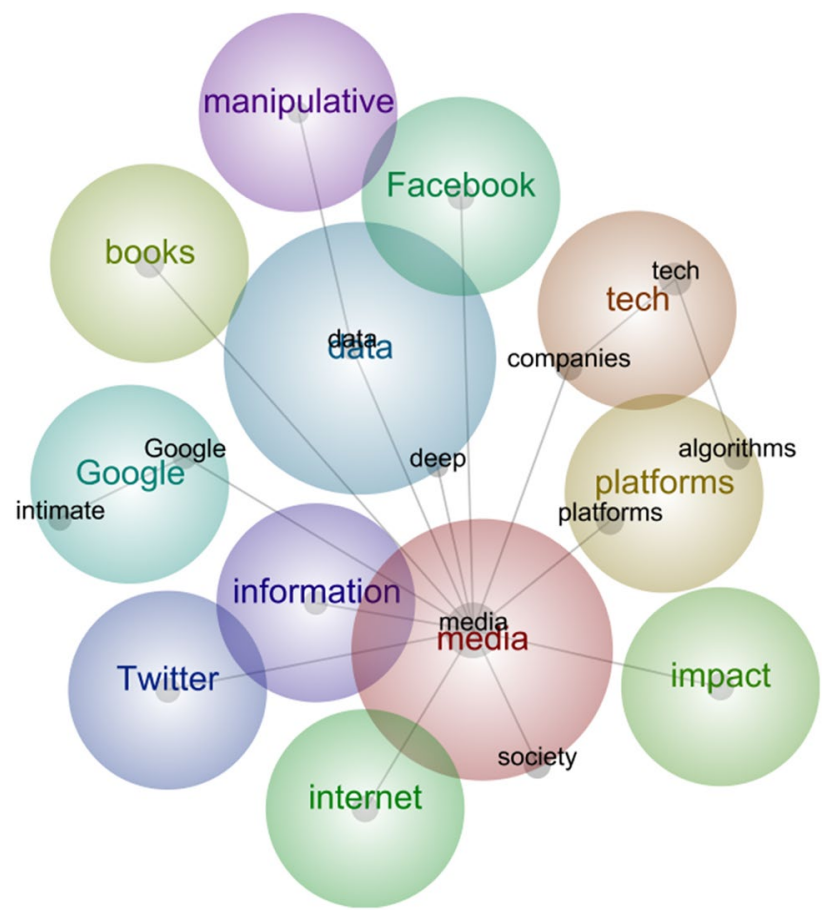

Fig. 1 Twitter themes on the social dilemma

\section{References}

Friestad, M., and P. Wright. 1995. Persuasion knowledge: Lay people's and researchers' beliefs about the psychology of advertising. Journal of Consumer Research 22 (1): 62. https://doi. org/10.1086/209435.

Friestad, M., and P. Wright. 1994. The Persuasion knowledge model: How people cope with Persuasion attempts. Journal of Consumer Research 21 (1): 1. https://doi.org/10.1086/209380.

Girish, D. 2020. 'The Social Dilemma' Review: Unplug and run. The New York Times. https://www.nytimes.com/2020/09/09/movies/ the-social-dilemma-review.html.

Kirmani, A., and M.C. Campbell. 2004. Goal seeker and persuasion sentry: How consumer targets respond to interpersonal marketing persuasion. Journal of Consumer Research 31 (3): 573-582. https ://doi.org/10.1086/425092.

Krishen, A.S., R.L. Raschke, A.G. Close, and P. Kachroo. 2017. A power-responsibility equilibrium framework for fairness: Understanding consumers' implicit privacy concerns for location-based services. Journal of Business Research 73 (4): 20-29. https://doi. org/10.1016/j.jbusres.2016.12.002.

Martin, K.D., and P.E. Murphy. 2017. The role of data privacy in marketing. Journal of the Academy of Marketing Science 45: 135155. https://doi.org/10.1007/s11747-016-0495-4.

Morgese, J. 2020. 3 reforms social media platforms should make in light of 'The Social Dilemma'. TechCrunch. https://techcrunch .com/2020/10/22/3-reforms-social-media-platforms-should-makein-light-of-the-social-dilemma/?guccounter $=1 \&$ guce_refer rer $=$ aHR0cHM6Ly93d3cuZ29vZ2xlLmNvbS8\&guce_referrer_ sig=AQAAAJBGr9CDBmeUw7y7wukRyt9ZOaABmWsLSpZu mQ0pwi5B9ARue6PZNFSG5Npq5GqWOWSIt6KU_FDd5CjH30g8TT0BZSd3ula8Q4_6mch4SFtPN2yrZyL-P2F_sYQ4n kRUkCY2w5weHtlZm2ZQmKprQCcrQceWaelFiA4LRdzc7xP.

Petrescu, M., A. Krishen, and M. Bui. 2020. The internet of everything: Implications of marketing analytics from a consumer policy perspective. Journal of Consumer Marketing 37 (6): 675-686. https ://doi.org/10.1108/JCM-02-2019-3080.

Petrescu, M., and A.S. Krishen. 2018. Analyzing the analytics: Data privacy concerns. Journal of Marketing Analytics 6: 41-43. https ://doi.org/10.1057/s41270-018-0034-x.

Raschke, R., A.S. Krishen, and P. Kachroo. 2014. Understanding the components of information privacy threats for location-based services. Journal of Information Systems 28 (1): 227-242.

Tucker, C.E. 2014. Social networks, personalized advertising, and privacy controls. Journal of Marketing Research 51 (5): 546-562.

Publisher's Note Springer Nature remains neutral with regard to jurisdictional claims in published maps and institutional affiliations.

Maria Petrescu is an Associate Professor of Marketing at International University of Monaco, Inseec U. Research Center. Her main research areas include marketing analytics and digital marketing. She has published articles in journals such as Psychology \& Marketing, the Journal of Marketing Management, Public Management Review, Journal of Product and Brand Management, the Journal of Retailing and Consumer Services, and the Journal of Internet Commerce.

Anjala S. Krishen is a Professor of Marketing and International Business and Director of MBA Programs at University of Nevada, Las Vegas, and has a B.S. in Electrical Engineering from Rice University, and an M.S. Marketing, MBA, and Ph.D. from Virginia Tech. She held management positions for 13 years before pursuing a doctorate. As of 2019, she has published over 50 peer-reviewed journal papers in journals including Journal of Business Research, Psychology \& Marketing, Information \& Management, European Journal of Marketing, Journal of Travel \& Tourism Marketing, and Journal of Marketing Education. In 2016, she gave a TEDx talk (at UNR) titled "Opposition: The light outside of the dark box," and a UNLV Creates speech entitled "Consuming to Creating, Watching to Doing, Seeing to Being." To date, she has completed over 55 marathons, seven ultramarathons, and three 100 milers and has a black belt in Taekwondo. 